\title{
Aplikasi medan magnet pada saluran bahan bakar sepeda motor
}

\author{
I Made Mara ${ }^{1) \star}$, I Made Nuarsa ${ }^{1)}$ \\ ${ }^{1}$ Jurusan Teknik Mesin Universitas Mataram, Jalan Majapahit 62 Mataram
}

Naskah diterima 20/06/2021; direvisi 21/09/2021; disetujui 30/09/2021

doi: https://doi.org/10.24843/JEM.2021.v14.i02.p02

\begin{abstract}
Abstrak
Penghematan pemakaian bahan bakar pada mesin kendaraan menjadi hal yang sangat penting disamping memperbaiki kualitas bahan bakar sehingga emisi gas buang yang dikeluarkan mesin menjadi lebih ramah lingkungan. Dalam penelitian ini medan magnet dipasang pada saluran bahan bakar dengan tujuan agar bahan bakar terkena pengaruh medan magnet. Medan magnet tersebut didapat dari magnet elektromagnetik dan juga magnet permanen. Konsumsi bahan bakar diuji pada mesin sepeda motor yang menggunakan sistem karburator dan juga pada mesin yang menggunakan system injeksi bahan bakar. Emisi gas buang yang diamati adalah gas buang $\mathrm{CO}$ dan $\mathrm{HC}$ dengan menggunakan alat uji emisi gas buang. Hasil penelitian menunjukkan bahwa bahwa penggunaan medan magnet yang dipasang pada saluran bahan bakar dapat menurunkan konsumsi bahan bakar mesin sepeda motor baik yang menggunakan sistem karborator maupun sistem injeksi bahan bakar yaitu sebesar rata-rata $18 \%$. Penggunaan medan magnet juga menunjukkan pengaruh yang sangat baik dalam menurunkan emisi gas buang mesin sepeda motor. Panjang magnet yang terpasang pada saluran bahan bakar $80 \mathrm{~mm}$ menghasilkan angka penurunan emisi gas buang CO sebesar $80 \%$ - 90\% dan HC sebesar $60 \%-77 \%$. Prosentase penurunan ini lebih baik dibandingkan dengan panjang magnet lainnya.
\end{abstract}

Kata kunci: Medan magnet, emisi gas buang, konsumsi bahan bakar, magnet permanen

\begin{abstract}
Reducing fuel consumption and improving fuel quality in motorcycle engines are very important in order to make the exhaust gas emission from the engine becomes more environmentally friendly. In this study, a magnetic field is attached to the fuel line so that the fuel is affected by the magnetic field. The magnetic field is obtained from electromagnetic magnets and permanent magnets. Fuel consumption is tested on a motorcycle engine that it uses a carburetor system and on an engine that uses a fuel injection system. The exhaust emissions observed were $\mathrm{CO}$ and $\mathrm{HC}$ by using exhaust gas analyzer. The results showed that the use of a magnetic field mounted on the fuel line can reduce the fuel consumption of a motorcycle engine, using either a carborator system or a fuel injection system by an average of $18 \%$. The use of magnetic fields also shows a very good effect in reducing exhaust gas emissions from motorcycle engines. The length of the magnet attached to the fuel line, $80 \mathrm{~mm}$ provides a reduction in exhaust gas emissions of $\mathrm{CO}$ by $80 \%-90 \%$ and $\mathrm{HC}$ by $60 \%-77 \%$. The percentage reduction in exhause gas emission is better than the other length of magnets.
\end{abstract}

Keywords: Magnetic field, exhaust gas emission, fuel consumption, permanen magnet

\section{Pendahuluan}

Polusi yang ditimbulkan dari pemakaian bahan bakar minyak yang berasal dari minyak bumi selain mencemari udara juga mengakibatkan dampak negatif yang begitu nyata terhadap perubahan iklim, cuaca, serta suhu lingkungan. Sumber pencemaran udara terbesar berasal dari kendaraan bermotor. Polusi yang dihasilkan oleh kendaraan bermotor di Indonesia dari tahun ke tahun menunjukan peningkatan. Bahkan kota Jakarta tercatat sebagai kota dengan tingkat polusi udara ke tiga terparah di dunia [1]. Hal ini diperkuat dengan adanya peningkatan jumlah kendaraan sepeda motor yakni sampai tahun 2019, jumlah sepeda motor yang ada di Indonesia mencapai 112.771.136 unit dan menurut data BPS jumlah tersebut selalu mengalami kenaikan sekitar lebih dari $5 \%$ pertahunnya.

Penghematan bahan bakar menjadi sesuatu yang sangat penting dengan semakin tingginya perhatian terhadap kelestarian lingkungan. Selain penghematan bahan bakar, memperbaiki kualitas bahan bakar juga perlu dilakukan sehingga akan menghasilkan emisi gas buang yang ramah lingkungan. Selain menggunakan bahan bakar alternatif yang ramah lingkungan, cara lain untuk mengurangi polusi adalah dengan meningkatkan efisiensi motor bakar. Berbagai cara telah diupayakan dan diterapkan untuk meningkatkan efisiensi termal motor bakar, antara lain dengan meningkatkan efisiensi pembakaran dengan meningkatkan perbandingan kompresi, electronics fuel injection dan variable valve timing. Sedangkan alat dan bahan aditif yang digunakan sebagai penghemat bahan bakar yaitu bahan aditif berupa tablet, cairan (Fuel Booster) dan yang berupa peralatan misalnya difusor yang dipasang di dalam karburator, dan magnetic fuel saver (penghemat bahan bakar magnetis) [2]. Penurunan konsumsi bahan bakar pada mesin bensin 2 tak mencapai

\footnotetext{
*Korespondensi: Tel.: +6281917967987

E-mail:made.mara@unram.ac.id
} 
$14 \%$ dengan penggunaan magnet permanen pada saluran bahan bakar [3].

Penghematan bahan bakar minyak menjadi sesuatu yang sangat penting. Selain penghematan, memperbaiki kualitas bahan bakar minyak juga perlu dilakukan sehingga akan menghasilkan emisi gas buang yang ramah lingkungan. Selain menggunakan bahan bakar alternatif yang ramah lingkungan, cara lain untuk mengurangi polusi adalah dengan meningkatkan efisiensi pembakaran pada mesin pembakaran dalam [4]. Penurunan emissi gas buang dengan menggunakan medan magnet permanen yang dipasang pada saluran bahan bakar juga telah diungkap dalam penelitian pengaruh magnetisasi bahan bakar terhadap unjuk kerja mesin dan emisi gas buang [5].

Viskositas bahan bakar hidrokarbon menurun ketika diterapkan medan magnet karena molekul bahan bakar hidrokarbon mengalami declustered dan menyebabkan atomisasi yang lebih baik dari bahan bakar, baik dari campuran bahan bakar dan udara, menurunkan jumlah bahan bakar yang tidak terbakar dan peningkatan efisiensi termal. Secara keseluruhan proses alat magnetisasi bisa dianggap dengan pemberian medan elektromagnet bisa mengurangi konsumsi pemakaian bahan bakar hingga mencapai 20\% [6]. Dan bila ditinjau dari kandungan emisi gas buang maka penerapan medan elektromagnet juga bermanfaat dengan menurunkan emisi gas buang yang berbahaya seperti gas $\mathrm{CO}$ dan $\mathrm{HC}$. Hal ini bisa mengindikasikan bahwa ruang bakar menghasilkan pembakaran sempurna. Teknologi pemberian medan magnet pada bahan bakar bisa menjadi solusi untuk mengurangi global warming dan menyebabkan gas buang kendaraan ramah lingkungan [6].

Penggunaan medan magnet telah banyak dilakukan seperti untuk meningkatkan kualitas pembakaran dan peningkatan unjuk kerja pada mesin diesel [7], penurunan konsumsi bahan bakar pada mesin diesel [8]. Medan magnet digunakan sebagai usaha mengionisasi bahan bakar agar peningkatan efisiensi termal dan pengurangan tingkat emisi dalam mesin diesel telah diteliti pula [9].

Namun demikian belum ada penjelasan yang lebih detail model medan magnet yang diaplikasikan, baik jenis magnet yang dipakai, metode peletakannya pada saluran bahan bakar. Oleh karena itu dalam penelitian ini akan diteliti penggunaan jenis magnet dan perletakan medan magnet pada saluran bahan bakar dan pengaruhnya terhadap konsumsi bahan bakar dan emisi gas buang mesin sepeda motor empat langkah satu silinder.

Tujuan penelitian ini ingin mengetahui pengaruh medan magnet terhadap konsumsi bahan bakar dan emisi gas buang yang dikeluarkan oleh mesin sepeda motor yang menggunakan sistem karburator dan sistem injeksi bahan bakar.

\section{Metode Penelitian}

Pengaruh medan magnet yang dipasang pada saluran bahan bakar mesin sepeda motor akan dipelajari dan diuji dalam penelitian ini. Ada dua jenis medan magnet yang dipergunakan dalam penelitian ini yaitu medan magnet elektromagnetik yang berasal dari lilitan kawat tembaga yang dialiri arus listrik, di mana arus listriknya diambil dari baterai sepeda motor tersebut. Medan magnet yang kedua didapat dari magnet permanen jenis neodymium yang berbentuk cincin. Kekuatan medan magnet elektromagnetik rata-rata 462 Gauss untuk medan magnet elektromagnetik memanjang dan 414 Gauss untuk medan magnet elektromagnetik melintang. Sedangkan medan magnet permanen neodymium yaitu rata-rata 151 Gauss untuk Panjang 40 mm, 159 Gauss untuk panjang $60 \mathrm{~mm}$ dan 165 Gauss untuk panjang 80 $\mathrm{mm}$. Pada penelitian ini pengaruh dari medan magnet tersebut terhadap pemakaian bahan bakar dan emisi gas buang mesin sepeda motor akan diuji pada sistem yang menggunakan karburator (Honda Impresa) dan juga mesin sepeda motor yang menggunakam system injeksi bahan bakar (Honda Vario 110), sedangkan bahan bakar yang dipergunakan adalah bahan bakar bensin jenis pertamak produksi pertamina. Adapun rancangan medan magnet yang digunakan digambarkan pada Gambar 1.
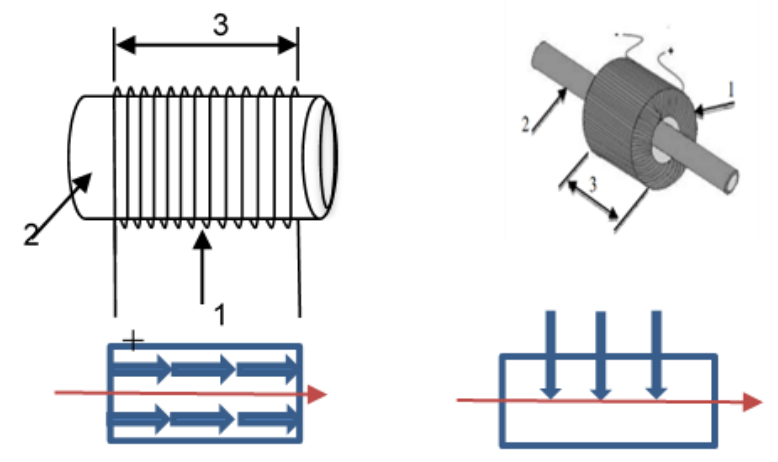

Gambar 1. (a). Medan magnet mamanjang, (b). lilitan medan magnet melintang. 1. kawat kumparan, 2. saluran bahan bakar, 3. panjang lilitan

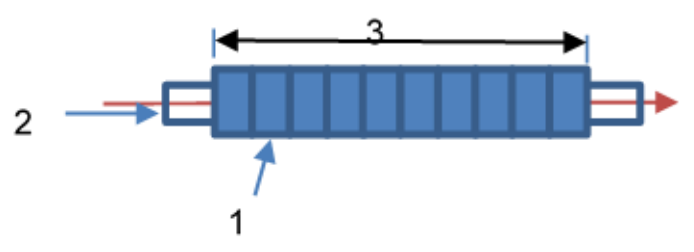

Gambar 2. Magnet permanen neodymium, 2. saluran bahan bakar, 3. panjang magnet Selanjutnya rangkaian alat uji disusun sedemikian rupa agar pelaksanaan pengujian emisi, pemakaian bahan bakar dapat dilakukan 
dengan baik. Adapun susunan alat uji dapat dilihat seperti Gambar 3.

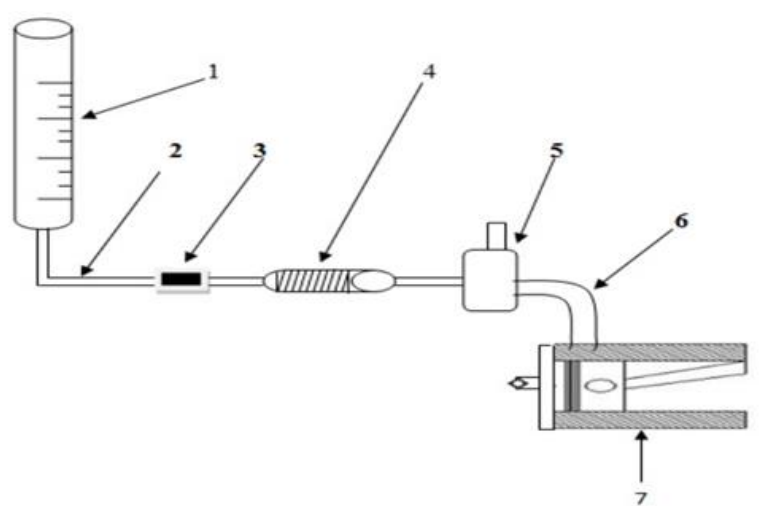

Gambar 3. Skema alat uji. 1. gelas ukur, 2. saluran bahan bakar, 3. saringan bahan bakar, 4. alat magnetasi bahan bakar, 5. Karburator/injektor, 6 . intake manifold, 7. ruang bakar mesin.

\section{Hasil dan Pembahasan}

3.1 Pengaruh medan magnet elektromagnetik dan magnet permanen terhadap konsumsi bahan bakar

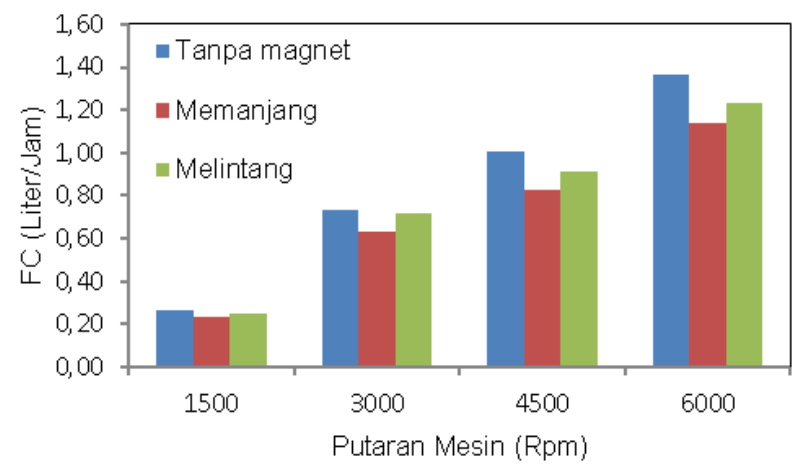

Gambar 4. Pengaruh medan magnet elaktromagnetik terhadap pemakaian bahan bakar dalam liter/jam pada mesin sistem karburator

Pada gambar 4 di atas terlihat bahwa pada pengujian penggunaan medan magnet pada saluran bahan bakar secara elektromagnetik mengalami penurunan konsumsi bahan bakar dibandingkan dengan tanpa penggunaan medan magnet di setiap putaran mesin. Penurunan konsumsi bahan bakar sebesar $18 \%$ pada 6000 rpm dengan penggunaan magnet memanjang dibandingkan dengan tanpa menggunakan medan magnet.

Gambar 5 memperlihatkan trend penurunan konsumsi bahan bakar pada berbagai putaran mesin. Semakin tinggi putaran mesin tentu jumlah bahan bakar yang dikonsumsi akan semakin besar karena jumlah siklus pembakaran yang terjadi semakin banyak. Jika dibandingkan pemakaian bahan bakar antara bahan bakar yang tidak terkena pengaruh magnet (tanpa magnet) dengan bahan bakar yang terkena pengaruh magnet terlihat bahwa terjadi penurunan konsumsi bahan bakar jika bahan bakar tersebut terkena pengaruh magnet. Terlihat juga bahwa medan magnet yag lebih panjang menunjukkan penurunan konsumsi bahan bakar yang lebih banyak dibandingkan dengan medan magnet yang lebih pendek. Penurunan konsumsi bahan bakar paling besar yaitu $18.09 \%$ didapat pada mesin sepeda motor yang menggunakan medan magnet dengan panjang magnet $80 \mathrm{~mm}$ pada putaran mesin 6000 rpm.

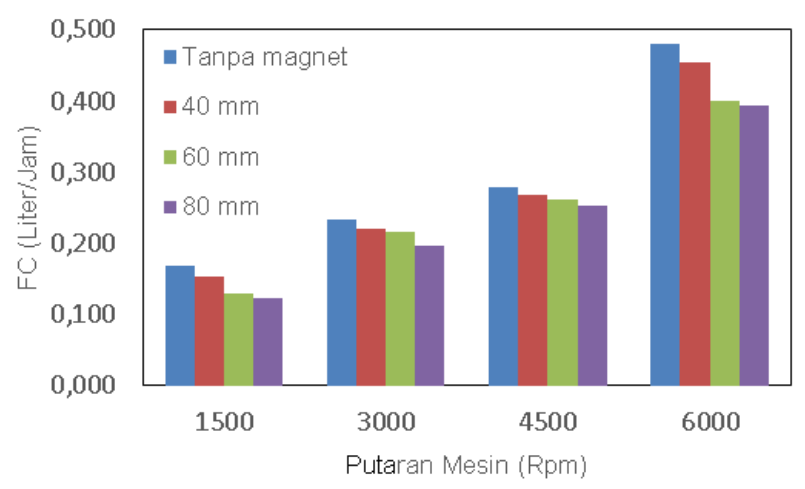

Gambar 5. Pengaruh medan magnet terhadap pemakaian bahan bakar dalam liter/jam pada mesin sistem injeksi bahan bakar

Medan magnet dapat menyebabkan bahan bakar terpengaruh atau menjadi lebih reaktif mengikat oksigen sehingga lebih mudah terbakar, oleh karena itu mesin mengkonsumsi lebih sedikit bahan bakar utnuk menghasilkan daya yang sama pada putaran tersebut. Bahan bakar pertamax yang terkena pengaruh medan magnet akan lebih mudah untuk menguap sehingga lebih cepat terbakar.
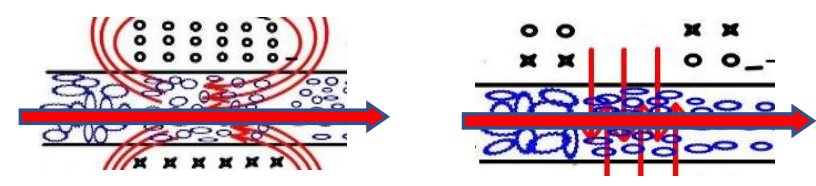

Gambar 6. Ilustrasi aliran bahan bakar yang terkena medan magnet. A. memanjang, B melintang

Penurunan konsumsi bahan bakar ini juga diungkap dalam [10] di mana penurunan konsumsi bahan bakar solar mencapai $14 \%$. Dalam penelitian [3] juga mendapatkan penurunan konsumsi bahan bakar yang cukup besar akibat terkena pengaruh medan magnet. Penurunan konsumsi bahan bakar juga diperoleh pada mesin yang menggunakan sistem injeksi bahan bakar dengan tingkat penurunan konsumsi bahan bakar dengan trend yang sama.

3.2 Pengaruh medan magnet terhadap emisi gas buang mesin sepeda motor 
Gambar 7 memperlihatkan besaran gas buang $\mathrm{CO}$ yang dikeluarkan oleh mesin Honda Vario $110 \mathrm{cc}$ akibat medan magnet yang dipasang pada saluran bahan bakar sebelum injektor.

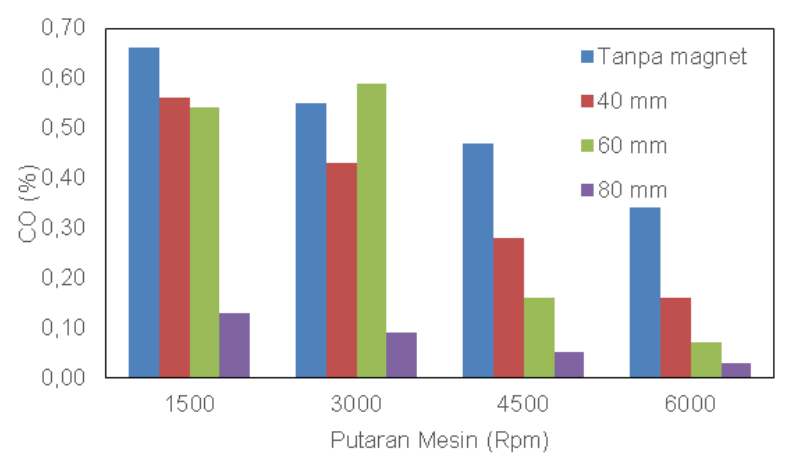

Gambar 7. Emisi gas buang CO

Gambar 7 memperlihatkan pengaruh medan magnet dan putaran mesin terhadap gas buang $\mathrm{CO}$ yang terbentuk. Pada setiap putaran mesin terlihat bahwa medan magnet yang dipasang pada saluran bahan bakar mampu menurunkan emisi gas buang $\mathrm{CO}$ yang dikeluarkan mesin sepeda motor Vario $110 \mathrm{cc}$. pada putaran mesin yang lebih tinggi terjadi kecendrungan gas buang $\mathrm{CO}$ yang terbentuk lebih sedikit, akibat pembakaran bahan bakar di dalam ruang bakar lebih sempurna. Panjang magnet juga secara umum turut mempengaruhi jumlah gas buang $\mathrm{CO}$ yang terbentuk.

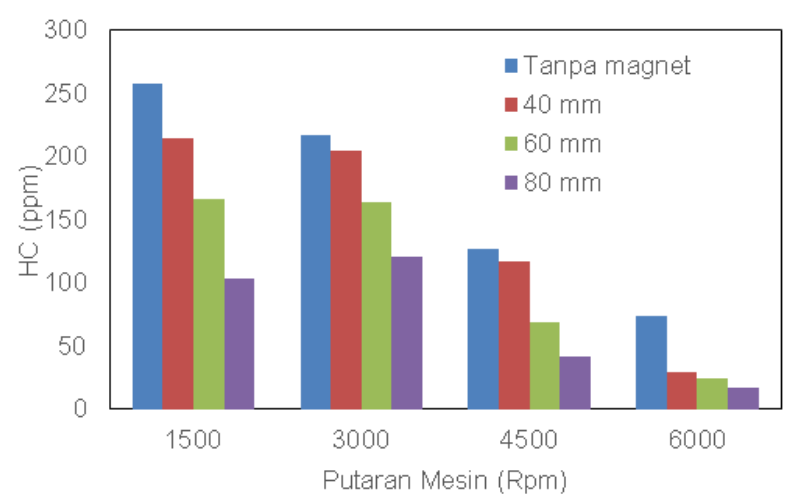

Gambar 8 Emisi gas buang HC

Bahan bakar yang mendapat pengaruh medan magnet memiliki kecendrungan lebih reaktif mengikat oksigen akibat lebih mudahnya bahan bakar tersebut menguap sehingga dapat terbakar lebih cepat dan lebih baik. Oleh karena pembakaran yang terjadi lebih baik sehingga gas buang $\mathrm{CO}$ yang terbentuk menjadi lebih sedikit. Pada putaran mesin 6000 rpm jika dibandingkan antara bahan bakar yang tidak terkena pengaruh magnet dengan bahan bakar yang terkena pengaruh magnet terjadi penurunan emisi gas buang CO antara $80.30 \%$ - 91.18\%. Panjang magnet $80 \mathrm{~mm}$ cendrung mengeluarkan emisi gas buang $\mathrm{CO}$ yang lebih rendah dibandingkan panjang magnet yang lebih pendek. Penurunan emisi gas buang ini juga terjadi akibat melemahnya ikatan atom hidrokarbon akibat terkena pengaruh medan magnet [3], sehingga terbakar lebih sempurna. Penurunan emisi gas buang CO sampai 90\% [11] pada mesin empat langkah 1 silinder dengan bahan bakar bensin.

Gas buang $\mathrm{HC}$ yang dikeluarkan mesin sepeda motor Vario 110 cenderung mengalami penurunan dengan meningkatnya putaran mesin dari sekitar 104-258 ppm pada putaran mesin $1500 \mathrm{rpm}$ menjadi $17-74 \mathrm{ppm}$ pada putaran mesin $6000 \mathrm{rpm}$. Jika dilihat pemasangan medan magnet pada saluran bahan bakar, tampak bahwa magnet yang lebih Panjang $80 \mathrm{~mm}$ memberikan pengaruh yang lebih besar dibandingkan dengan panjang magnet yang lainnya di semua putaran mesin. Penurunan kadar emisi gas buang HC didapat sekitar $59,69 \%-77,03 \%$ yaitu pada penggunaan magnet $80 \mathrm{~mm}$.

Medan magnet yang dipasang pada saluran bahan bakar menyebabkan bahan bakar mengalami gangguan medan magnet sehingga menyebabkan bahan bakar menjadi lebih reaktif mengikat oksigen, hal ini akan menyebabkan proses pembakaran bahan bakar menjadi lebih cepat dan menjadi lebih sempurna [8]. Medan magnet membuat ikatan molekul bahan bakar hidrokarbon menjadi lebih lemah, partikel bahan bakar menjadi lebih kecil [12] sehingga efisiensi pembakaran menjadi lebih baik[13].

\section{Simpulan}

Dari hasil pembahasan di atas dapat disimpulkan bahwa penggunaan medan magnet yang dipasang pada saluran bahan bakar dapat menurunkan konsumsi bahan bakar mesin sepeda motor baik yang menggunakan sistem karborator maupun sistem injeksi bahan bakar yaitu sebesar rata-rata $18 \%$. Penggunaan medan magnet juga menunjukkan pengaruh yang sangat baik dalam menurunkan emisi gas buang mesin sepeda motor. Panjang magnet yang terpasang pada saluran bahan bakar $80 \mathrm{~mm}$ menunjukkan angka penurunan emisi gas buang $\mathrm{CO}$ sebesar $80 \%$ $90 \%$ dan HC sebesar $60 \%-77 \%$. Prosentase penurunan ini lebih baik dibandingkan dengan panjang magnet lainnya.

\section{Ucapan Terima Kasih}

Penulis mengucapkan banyak terima kasih kepada Jurusan Teknik Mesin Fakultas Teknik Universitas Mataram atas dukungan fasilitas dalam penyelesaian tulisan ini, dan penghargaan yang setinggi-tinginya atas dukungan dari rekan sehingga tulisan ini dapat terselesaikan pada waktunya. 


\section{Daftar Pustaka}

[1] I. M. Mara, I. B. Alit, and I. M. Nuarsa, Penurunan Konsumsi Bahan Bakar pada Mesin Bensin 4 Langkah 1 Silinder Dengan Menggunakan Medan Magnet Elektomagnetik, Din. Tek. Mesin, vol. 11, no. 1, p. 49, 2021, doi: 10.29303/dtm.v11i1.374.

[2] R. Guerrero Torres and M. Mehrvar, An Experimental Evidence of Gasoline Ionization by a Magnetic Field, Proc. 2nd Int. Conf. Recent Trends Environ. Sci. Eng., no. 144, pp. 1-8, 2018, doi: 10.11159/rtese18.144.

[3] A. S. Faris et al., Effects of magnetic field on fuel consumption and exhaust emissions in two-stroke engine, Energy Procedia, vol. 18, pp. 327-338, 2012, doi: 10.1016/j.egypro.2012.05.044.

[4] I. M. Mara, I. W. Joniarta, I. B. Alit, I. M. A. Sayoga, and M. Nuarsa, Analisis Penggunaan Alat Magnetisasi Bahan Bakar Secara Elektromagnetik Terhadap Unjuk Kerja Mesin Empat Langkah Satu Silinder, Din. Tek. Mesin, vol. 8, no. 2, pp. 98-103, 2018, doi: 10.29303/dtm.v8i2.233.

[5] F. A. El Fatih and G. M. Saber, Effect Of Fuel Magnetism on Engine Performance And Emissions, Aust. J. Basic Appl. Sci., vol. 4, no. 12, pp. 6354-6358, 2010.

[6] N. Fuhaid, M. A. Sahbana, and A. Arianto, Pengaruh Medan Elektromagnet Terhadap Konsumsi Bahan Bakar dan Emisi Gas Buang pada Motor Bensin, Proton, vol. 3, no. 1, pp. 1-9, 2011.

[7] V. Ugare, S. Dhoble, S. Lutade, and K. Mudafale, Performance of Internal Combustion (Cl) Engine Under The Influence of Stong Permanent Magnetic Field, J. Mech. Civ. Eng., vol. 2014, no. Ci, pp. 11-17, 2014.

[8] C. Y. Chen, W. J. Lee, J. K. Mwangi, L. C. Wang, and J. H. Lu, Impact of Magnetic Tube on Pollutant Emissions from The Diesel Engine, Aerosol Air Qual. Res., vol. 17, no. 4, pp. 1097-1104, 2017, doi: 10.4209/aaqr.2016.11.0478.

[9] P. V. Kumar, S. K. Patro, and V. Pudi, Experimental Study of A Novel Magnetic Fuel Ionization Method in Four Stroke Diesel Engines, Int. J. Mech Eng. Rob. Res., vol. 3, no. 1, pp. 151-159, 2014.

[10] P. Sathiamurthi, K. S. Karthi Vinith, and A. Sivakumar, Performance And Emission Test in $\mathrm{Cl}$ Engine Using Magnetic Fuel Conditioning with Nano Additives, Int. J. Recent Technol. Eng., vol. 8, no. 3, pp. 78237826 , 2019 ,

doi: 10.35940/ijrte.C6213.098319.

[11] D. R. Mane and V. S. Sawant, A Comparative Study of Effect of Magnetic Field on Exhaust Emission In Internal Combustion Engine, IOSR J. Appl. Phys., Vol. 7, No. 6, Pp. 38-40, 2015, Doi: 10.9790/4861-07623840.
[12] S. Chavan And P. Jhavar, Effects $f$ Application Of Magnetic Field On Efficiency Of Petrol Engine., Int. Res. J. Eng. Technol., Vol. 03, No. 09, Pp. 152-161, 2016.

[13] R. A. Tamol, Sr., And VA, Method and Apparatus To Increase Combustion Efficiency and To Reduce Exhaust Gas Pollutants from Combustion of A Fuel, Vol. 1, No. 12, P. Vol 1, Nos. 12, 2005, 2005.

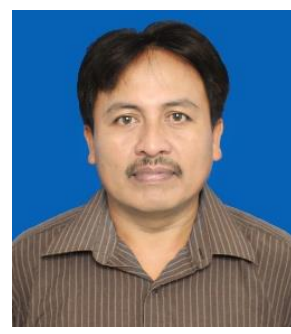

I Made Mara ST., M.Sc menyelesaikan pendidikan S1 Teknik Mesin di Universitas Udayana pada tahun 1997. Pendidikan Master of Science dalam bidang International Automotive Engineering diselesaikan di Universitas of Herfordshire di Inggris dan Fachhochschule Hamburg di German pada tahun 2001 dengan area riset bahan bakar, internal combustion engine, EBT.

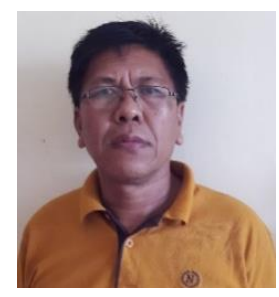

I Made Nuarsa ST., MT menyelesaikan studi program sarjana di Jurusan Teknik Mesin Universitas Udayana tahun 1994. Ia melanjutkan studi program sarjana di ITS Surabaya dan memperoleh gelar MT tahun 2008. Area penelitian yang diminati adalah Konversi Energi, Teknik Pendingin dan sejenisnya. 